\title{
Functional Compartmentation of Glycolytic Versus Oxidative Metabolism in Isolated Rabbit Heart
}

\author{
James Weiss and Bradley Hiltbrand \\ Department of Medicine and the American Heart Association Greater Los Angeles Affiliate Cardiovascular Research Laboratory, \\ University of California Los Angeles School of Medicine, Los Angeles, California 90024
}

\section{Abstract}

To investigate whether energy derived from glycolytic and oxidative metabolism are preferentially used for different functions in heart, tension, intracellular potential, and extracellular $\left[\mathrm{K}^{+}\right]$and $\mathrm{pH}$ (using triple barrel $\mathrm{K} / \mathrm{pH}$ electrodes, tip diameter $0.5 \mathrm{~mm}$ ) were monitored in isolated arterially perfused rabbit interventricular septa during exposure to hypoxia and metabolic inhibitors. Myocardial content of high energy phosphates, lactate, and glycogen were determined under the same conditions. Inhibiting oxidative metabolism with hypoxia, dinitrophenol $\left(10^{-5} \mathrm{M}\right)$, or Na-azide $\left(10^{-3} \mathrm{M}\right)$ caused marked suppression of tension (by $73 \pm 5,65 \pm 8$, and $50 \pm 14 \%$, respectively) and a small increase in $\left[\mathrm{K}^{+}\right]_{0}(0.8 \pm 0.4,0.5 \pm 0.25$, and $0.4 \pm 0.2 \mathrm{mM}$, respectively) after $10 \mathrm{~min}$. Inhibiting glycolysis with iodoacetate (IAA) $\left(10^{-3} \mathrm{M}\right)$ had a much smaller suppressant effect on tension $(28 \pm 24 \%)$ but markedly increased $\left[\mathrm{K}^{+}\right]_{0}$ accumulation (by $1.8 \pm 1.1 \mathrm{mM}$ ) at $10 \mathrm{~min}$. These differences, when IAA was compared individually to the other interventions, were highly significant. The shortening of action potential duration was not significantly different for the four interventions. $\mathrm{pH}_{0}$ increased slightly during IAA $(+0.04-+0.06 \mathrm{U})$ and fell during the other interventions $(-0.10--0.16 \mathrm{U})$, but this did not account for the differences in $\left[\mathrm{K}^{+}\right]_{0}$ accumulation and tension between inhibition of glycolytic vs. oxidative metabolism. Except for hypoxia, total cellular content of high energy phosphates was not significantly depressed under the various conditions. This data suggests that energy from glycolysis is preferentially used to support sarcolemmal function (as manifested by $\mathrm{K}^{+}$loss), whereas oxidatively derived energy preferentially supports contractile function.

Indexing terms: cardiac metabolism, extracellular pH, metabolic inhibitors, hypoxia, extracellular $\mathrm{K}^{+}$accumulation, and glycolysis.

\section{Introduction}

In erythrocytes, evidence has been presented that high energy phosphates generated via glycolysis may be preferentially used to support specific cellular membrane functions (1). Conversely, in muscle it has been proposed that the creatine phosphate energy shuttle may be the preferential source of high energy

Address reprint requests to Dr. Weiss, UCLA Center for the Health Sciences, Los Angeles, CA 90024.

Received for publication 25 June 1984 and in revised form 24 September 1984.

J. Clin. Invest.

(c) The American Society for Clinical Investigation, Inc. 0021-9738/85/02/0436/12 \$1.00

Volume 75, February 1985, 436-447 phosphates for muscle contraction (2). In vascular smooth muscle a functional compartmentation of glycolytic vs. oxidative metabolism has been demonstrated recently by Paul (3), who showed that $\mathrm{Na}^{+}-\mathrm{K}^{+}$pump activity was closely linked to glycolytic flux whereas force development correlated with oxidative metabolism in this preparation. Several lines of evidence suggest that a similar compartmentation of glycolytic energy may exist in cardiac muscle. MacLeod and Daniel (4) found that in anoxic guinea pig papillary muscles, elevated glucose concentration prevented action potential shortening but had no effect on improving contractile force. Bricknell et al. $(5,6)$ found that during low flow ischemia in isolated rat hearts, enzyme release and the onset of ischemic contracture were greatly accelerated by concomitant inhibition of glycolysis compared to inhibition of oxidative metabolism, despite similar total cellular levels of high energy phosphates. Higgins and Bailey (7) reported similar results and have also found that susceptibility of cultured heart cells to attack by phospholipases was sensitive to the rate of glycolysis of the cells, but not to inhibition of oxidative ATP production (8).

Recently, Doorey and Barry (9) and Hasin and Barry (10) reported that in cultured chick embryo myocytes, membrane depolarization was more sensitive to inhibition of glycolytic than oxidative metabolism, whereas contractile amplitude was more affected by inhibition of oxidative metabolism. These studies are compatible with a functional compartmentation of metabolic processes in heart, in which high energy phosphates generated via glycolysis play a special role in the maintenance of cell membrane function, helping to prevent damage to the sarcolemma during ischemia and other interventions interfering with oxidative metabolism. In this report, a comprehensive evaluation of cardiac function in intact ventricular myocardium was made during interventions designed to influence selectively either glycolytic or oxidative metabolism, to determine whether high energy phosphates generated via these metabolic pathways are preferentially used for different functions in cardiac muscle. In particular, since both cellular $\mathrm{K}^{+}$loss and contractile force are suspected of being directly linked to the metabolic state, the effects of inhibition of glycolytic vs. oxidative metabolism on these parameters were closely examined. Tissue levels of high energy phosphates and other metabolites were also measured under the various conditions. The results support the hypothesis that energy stores are partially compartmentalized in the rabbit ventricle, and demonstrate that manifestations of compartmentation can be elicited in intact ventricular myocardium after brief perturbations of cardiac metabolism.

\section{Methods}

Experimental set-up. The preparation was the arterially perfused isolated rabbit interventricular septum. 2-3-kg adult New Zealand white rabbits were heparinized and given an overdose of pentobarbital before 
thoracotomy. After removing the heart, the septal artery was cannulated, and the interventricular septum isolated and mounted in a constant temperature $\left(37^{\circ} \mathrm{C}\right)$ nitrogen-filled chamber as described previously (11). A ligature placed at the apex of the preparation was tied to a variable capacitance tension transducer to record tension. The septum was stimulated at $75 \mathrm{bpm}$ with platinum electrodes (series 1800 stimulator, WP Instruments, Inc., New Haven, CT). A perfusion pump (Gilson Minipulse 2) maintained a constant physiologic flow of 1.75 $\mathrm{ml} / \mathrm{min}\left(1.5-2.5 \mathrm{ml} / \mathrm{g}\right.$ per min) of heated $37^{\circ} \mathrm{C}$ perfusate through the septal artery. Standard perfusate consisted of (in millimolar): $\mathrm{NaCl}$ $120, \mathrm{KCl} 4, \mathrm{CaCl}_{2} 1.5, \mathrm{NaHCO}_{3} 22, \mathrm{NaH}_{2} \mathrm{PO}_{4} 0.44, \mathrm{MgCl}_{2} 1$, dextrose 5.6, and pyruvate 3. Insulin (10 $\mathrm{U} / 1)$ was added in all experiments. $\mathrm{pH}$ was maintained at 7.3-7.4 by gassing with a mixture of $5 \% \mathrm{CO}_{2}$ and the balance $\mathrm{O}_{2}$ (control perfusion) or $\mathrm{N}_{2}$ (hypoxia experiments). In some experiments, $1-2.5 \times 10^{-5} \mathrm{M}$ 2,4-dinitrophenol (DNP), ${ }^{1} 10^{-3} \mathrm{M}$ sodium azide, $10^{-4}-10^{-3} \mathrm{M}$ iodoacetate (IAA), or $20 \mathrm{mM}$ 2-deoxyglucose were added to the perfusate. Dextrose, but not pyruvate, was excluded from perfusate containing iodoacetate or 2-deoxyglucose. The preparation was allowed to equilibrate at least $1 \mathrm{~h}$ in standard perfusate before experimental intervention. This preparation has been shown to maintain stable mechanical and metabolic function and $\mathrm{K}^{+}$balance for a period of 5-6 $\mathrm{h}(12-14)$.

Electrodes. Intracellular potential was recorded with flexibly mounted glass microelectrodes filled with $3 \mathrm{M} \mathrm{KCl}$ (15). A triple barrel $\mathrm{K} / \mathrm{pH}$ electrode, overall tip diameter $0.5 \mathrm{~mm}$, was used to measure extracellular $\mathrm{K}^{+}$and $\mathrm{pH}$. The $\mathrm{K}^{+}$barrel (tip diameter $0.2 \mathrm{~mm}$ ) was constructed by the method of Hill et al. (16). The solid state $\mathrm{pH}$ barrel $(0.1 \mathrm{~mm}$ diameter) was obtained commercially (Beetrode, WP Instruments, Inc., New Haven, CT). Response time of both electrodes is of the order of $0.1 \mathrm{~s}$. A reference barrel consisted of teflon-coated $\mathrm{Ag}$ wire $(0.13 \mathrm{~mm}$ diameter) whose tip $(1 \mathrm{~mm})$ had been exposed and chlorided. The three barrels were tied together using a fine suture. Signals were fed into high impedance $\left(10^{13} \mathrm{ohms}\right)$ preamplifiers and the $\mathrm{K}^{+}$and $\mathrm{pH}$ signals subtracted from the reference barrel signal by differential amplifiers. Each $\mathrm{K} / \mathrm{pH}$ electrode was calibrated at $37^{\circ} \mathrm{C}$ in at least four solutions of known $\left[\mathrm{K}^{+}\right]$and $\mathrm{pH}$ before and at the conclusion of each experiment, and the slope was calculated by linear regression analysis. The $\mathrm{K}^{+}$barrel and $\mathrm{pH}$ barrels typically yielded slopes of 60-61 and $52-57 \mathrm{mV} /$ decade change in concentration, respectively. Interference from other physiologiçal ions was negligible. After insertion in the preparation through a superficial cut in the endocardium, each electrode was calibrated in situ by varying the $\mathrm{K}^{+}$and $\mathrm{pH}$ of the perfusate, and repositioned if the predicted response was not obtained.

Metabolic assays. A separate group of preparations was mounted in the same way as described above; tension was recorded continuously, but no electrophysiological measurements were performed. Venous effluent was collected at timed intervals $(20 \mathrm{~s}$ collection time per sample) during various interventions and assayed by standard spectrophotometric techniques for lactate content (17). At the end of the intervention, the pins securing one end of the preparation were removed, and the preparation was lifted off the floor of the chamber using the suture connected to the tension transducer. While still being perfused, the preparation was then smash frozen between copper blocks precooled in liquid $\mathrm{N}_{2}$ and rapidly immersed and stored in liquid $\mathrm{N}_{2}$. A small portion of the preparation was weighed before and after drying at $100^{\circ} \mathrm{C}$ to assess dry weight per wet weight ratio (average value $0.13 \pm 0.01$ ), and the remainder was extracted with $0.5 \mathrm{M}$ perchloric acid. The value of the dry weight per wet weight ratio was slightly lower than previously reported in nonfreeze clamped septa (12), which is probably due to trapping of surface water and the full distension of the vascular space at the moment of rapid freezing of the preparation. Metabolite content is expressed per gram dry weight of tissue to minimize error from this source. Tissue content of ATP, ADP, AMP,

1. Abbreviations used in this paper: DNP, dinitrophenol; IAA, iodoacetate. phosphocreatine, and creatine were determined in duplicate using a Waters high-performance liquid chromatography system with a C-18 5-micron radial compression cartridge column, $0.4 \mathrm{M} \mathrm{NH}_{4} \mathrm{H}_{2} \mathrm{PO}_{4}$ solvent, $\mathrm{pH}, 4.0$, and an absorbance detector (model 440, Waters Associates, Milford, MA) operating at $214 \mathrm{~nm}$ wave length (17a). Tissue content of lactate and glycogen were measured spectrophotometrically by standard methods $(17,18)$ using a Beckman DU8 spectrophotometer.

Experimental protocols. In the electrophysiological experiments, after equilibration, each preparation was exposed to a 10-min episode of hypoxia and allowed to recover for $\sim 30 \mathrm{~min}$ before the experimental intervention. This was done in order to be able to compare the effect of the intervention to hypoxia in each preparation. If the effects of the intervention were reversible, then a second hypoxic episode was repeated $30 \mathrm{~min}$ after recovery from the intervention to assess reproducibility. Changes in tension (normalized with respect to the value immediately preceding the intervention), $\left[\mathrm{K}^{+}\right]_{0}, \mathrm{pH}_{0}$, and action potential duration were found to be quite reproducible between successive 10-min exposures to hypoxia provided a recovery period of $\geq 25 \mathrm{~min}$ was permitted between episodes. To be consistent with the electrophysiological experiments, the metabolic experiments followed a similar protocol in which a 10-min period of hypoxia followed by a 30-min recovery period preceeded the intervention being tested.

Data analysis. Analysis of variance with the Bonferroni approach was used to evaluate statistical significance. In the case of data that was normalized (e.g., tension measurements), the logarithms of the normalized data was used in the statistical analysis to avoid overestimation of significance. Data is presented as mean $\pm \mathrm{SD}$ in the text, and mean $\pm S E$ in the figures for graphical simplicity.

\section{Results}

Fig. 1 compares the effects of successive 10-min exposures to hypoxia, $10^{-5} \mathrm{M} \mathrm{DNP}$, and $10^{-3} \mathrm{M} \mathrm{Na}$ azide on $\left[\mathrm{K}^{+}\right]_{0}, \mathrm{pH}_{0}$ and tension and its first derivative in the same preparation. In each case, both glucose and pyruvate were present as substrate. The effect of these interventions (designed to suppress oxidative metabolism while leaving glycolysis intact) was to cause modest $\left[\mathrm{K}^{+}\right]_{0}$ and $\left[\mathrm{H}^{+}\right]_{0}$ accumulation and a major suppression of tension. Fig. 2 contrasts the effects of hypoxia and $10^{-3} \mathrm{M}$ IAA in another preparation. During exposure to IAA, an inhibitor of glycolysis, glucose was removed, but pyruvate remained as substrate for oxidative metabolism. After $10 \mathrm{~min}$, IAA caused greater $\left[\mathrm{K}^{+}\right]_{0}$ accumulation than hypoxia, but almost no suppression of twitch tension. Contracture also developed after several minutes of exposure to IAA which was progressive and irreversible, even after returning to normal perfusate. The contracture failed to relax when $\mathrm{Ca}^{++}$was omitted during the first several minutes of reperfusion. A slight increase in $\mathrm{pH}_{0}$ was consistent with the inhibition of glycolysis. Fig. 3 summarizes the effects of these interventions in all preparations tested. Changes in action potential duration over the 10-min exposure period are included. The findings show that inhibition of glycolysis with $10^{-3} \mathrm{M}$ IAA resulted in marked $\mathrm{K}^{+}$loss from the myocardium with a modest suppression of tension. In contrast, inhibition of oxidative metabolism with hypoxia, DNP, or Na azide was associated with only modest $\mathrm{K}^{+}$loss but a major reduction in tension. These differences were statistically significant (comparing IAA vs. hypoxia, DNP, or $\mathrm{Na}$ azide for $\left[\mathrm{K}^{+}\right]_{0}$ accumulation or tension suppression, $P<0.001$ ). Shortening of action potential duration was modest and similar under all conditions. $10^{-3} \mathrm{M}$ IAA caused a slight increase in $\mathrm{pH}_{0}$ (consistent with reduced glycolytic $\mathrm{H}^{+}$production), whereas inhibitors of oxidative 

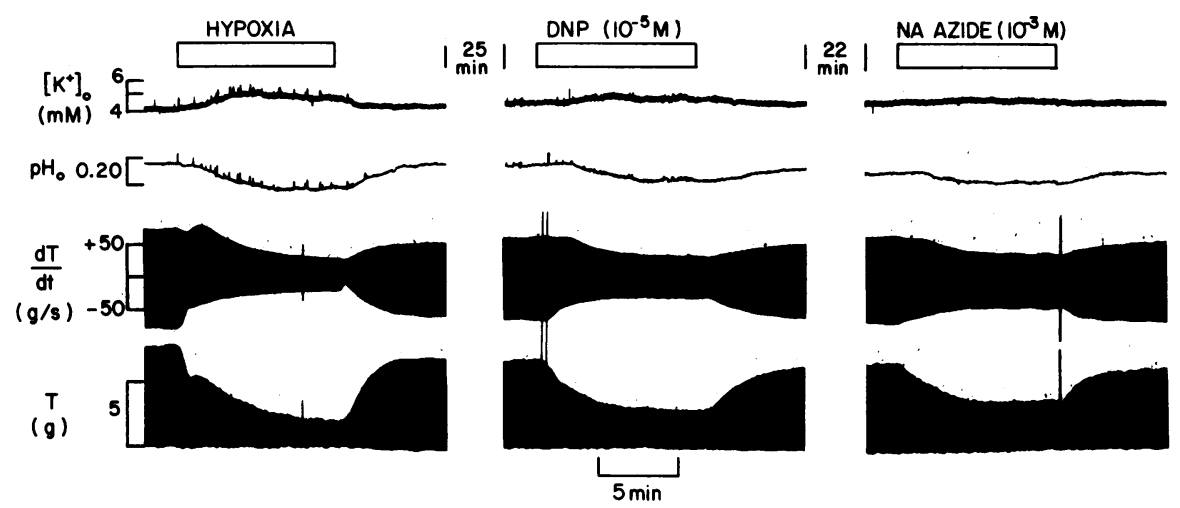

Figure 1. Effects of hypoxia, $10^{-5} \mathrm{M} 2-4$ DNP, and $10^{-3} \mathrm{M} \mathrm{Na}^{+}$azide on $\left[\mathrm{K}^{+}\right]_{0}$, $\mathrm{pH}_{0}$, and on tension and its first derivative (dT/dt). The same preparation was subjected to a 10-min exposure to each of the above interventions in succession, and allowed a 25-30 min recovery period in between. Glucose and pyruvate were present as substrate throughout. Temperature was $37^{\circ} \mathrm{C}$, and heart rate $75 \mathrm{bpm}$. metabolism caused a modest fall in $\mathrm{pH}_{0}$ (consistent with enhanced glycolysis).

Figs. 4-6 and Table I compare the myocardial levels of ATP, ADP, AMP, phosphocreatine, creatine, lactate, and glycogen after $10 \mathrm{~min}$ exposure to each of these interventions. Fig. 7 shows the venous lactate efflux rate as a function of time under each condition. During inhibition of glycolysis with $10^{-3} \mathrm{M}$ IAA, total cellular content of high energy phosphates was well maintained and was not significantly different from control (Figs. 4 and 5). Tissue lactate and glycogen content were slightly but not significantly reduced (Fig. 6). Lactate efflux rate fell to $60 \pm 8 \%$ of control in the presence of IAA. During inhibition of oxidative metabolism by DNP or $\mathrm{Na}$ Azide, tissue content of high energy phosphates was also not significantly different from control. Hypoxia, which produced the greatest reduction in tension, caused a slight fall in ATP (not statistically significant) and a significant decrease in phosphocreatine $(P<0.005)$ (Figs. 4 and 5). Tissue lactate tended to increase with no real change in glycogen content (Fig. 6), although the great variation in glycogen content between individual preparations was difficult to evaluate. Lac-

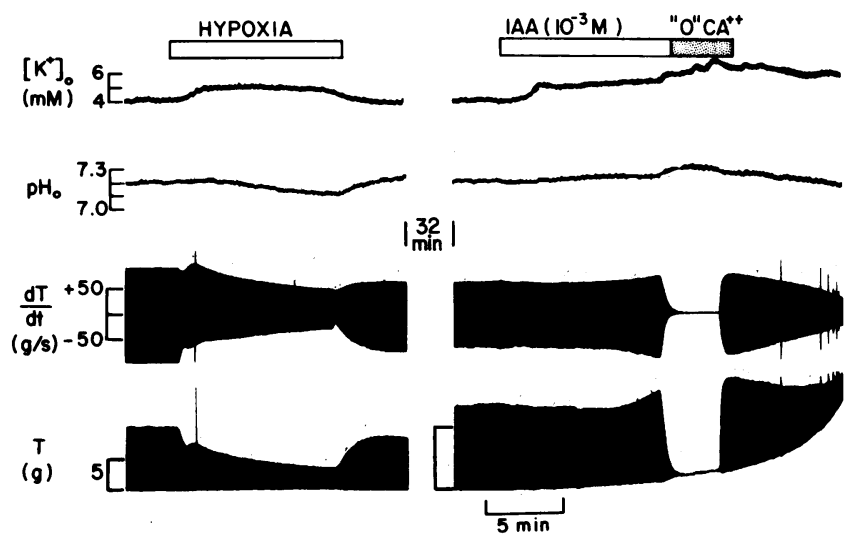

Figure 2. Comparison of the effects of hypoxia vs. $10^{-3} \mathrm{M}$ iodoacetate (IAA) on $\left[\mathrm{K}^{+}\right]_{0}, \mathrm{pH}_{0}$, and on tension and its first derivative (dT/ dt). A preparation was first exposed to a 10-min period of hypoxia (with glucose and pyruvate present as substrate). After an $\sim 30$-min recovery period, the same preparation was exposed for $10 \mathrm{~min}$ to glucose-free perfusate containing $10^{-3} \mathrm{M}$ IAA (with pyruvate present as substrate). Initial reperfusion for $3 \mathrm{~min}$ with control perfusate containing no added $\mathrm{Ca}^{++}\left(\right.$" 0 " $\left.\mathrm{Ca}^{++}\right)$failed to relax the reversible contracture caused by IAA. Temperature was $37^{\circ} \mathrm{C}$, and heart rate 75 bpm. tate efflux rate markedly increased in response to all three interventions interfering with oxidative metabolism (Fig. 7), with the largest increase occurring during hypoxia (506 $\pm 83 \%$



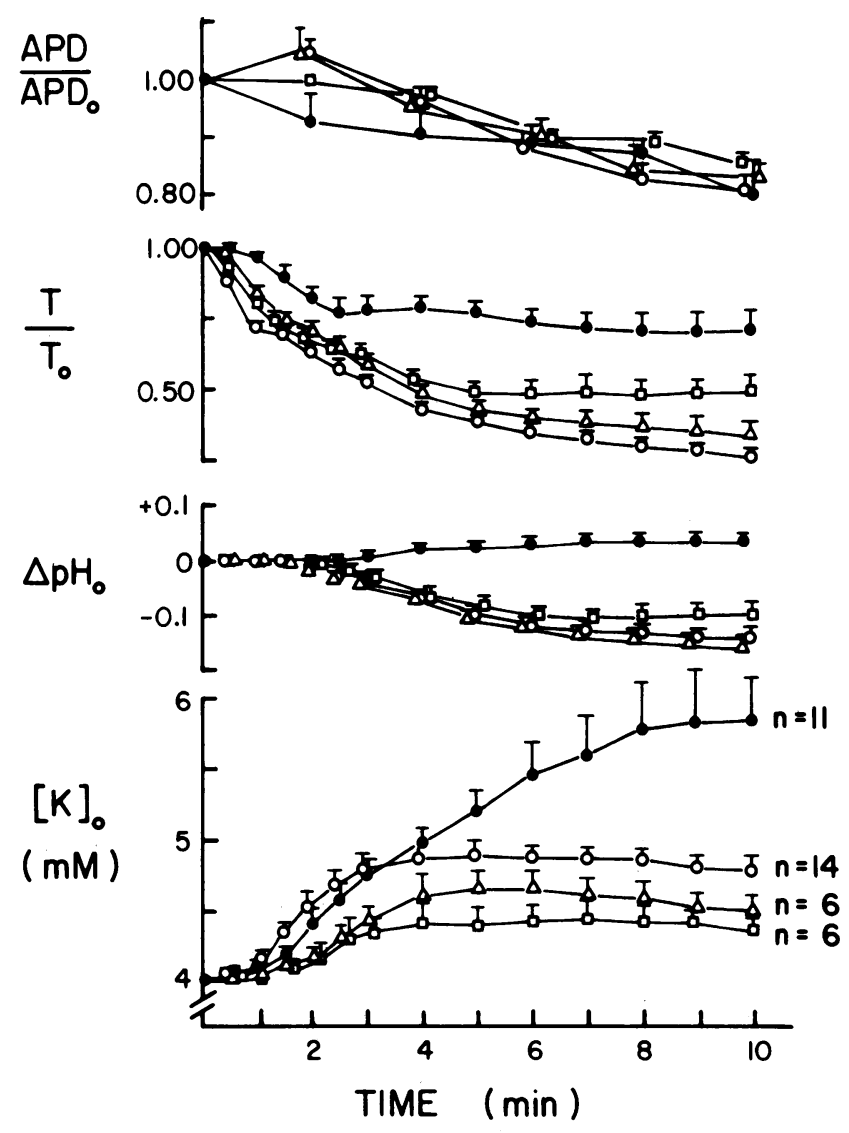

Figure 3. Comparison of effects of inhibition of glycolytic vs. oxidative metabolism on $\left[\mathrm{K}^{+}\right]_{0}, \mathrm{pH}_{0}$, tension $\left(\mathrm{T} / \mathrm{T}_{0}\right)$, and action potential duration (APD/APD $\mathrm{AP}_{0}$ ). Glycolysis was inhibited by adding $10^{-3} \mathrm{M}$ iodoacetate to glucose-free perfusate containing pyruvate as substrate (IAA, •). Oxidative metabolism was inhibited by hypoxia (0), $10^{-5} \mathrm{M}$ 2-4 dinitrophenol $(\Delta)$, or $10^{-3} \mathrm{M}$ sodium azide ( $\square$ ) with glucose and pyruvate present as substrate. Changes in tension and action potential duration were normalized to the control valve at time zero immediately preceding the intervention $\left(T_{0}\right.$ and $A P D_{0}$, respectively). Values shown are mean \pm SEM with the number of preparations indicated in parentheses. Temperature was $37^{\circ} \mathrm{C}$, and heart rate 75 bpm. 


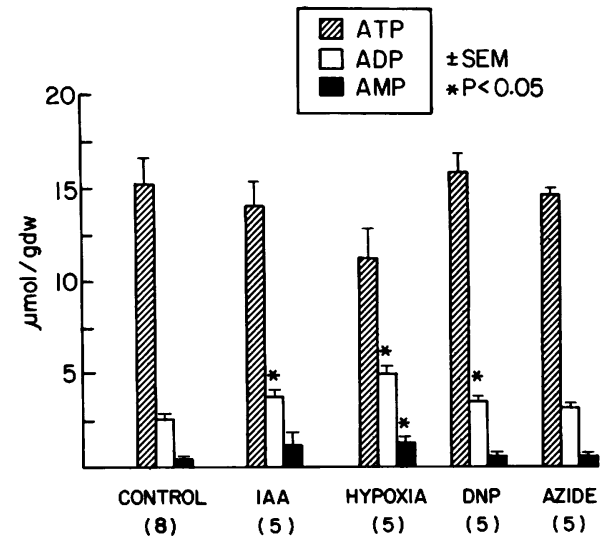

Figure 4. Myocardial content of ATP, ADP, and AMP after 10-min exposure to interventions designed to inhibit selectively glycolysis (IAA) or oxidative metabolism (hypoxia, DNP, azide). For more detailed description of specific interventions see legend to Fig. 3. Values represent mean \pm SEM with number of preparations indicated in parentheses. Asterisks indicate statistical significance $(P<0.05)$ compared with the control value. Temperature was $37^{\circ} \mathrm{C}$, and heart rate $75 \mathrm{bpm}$.

azide $(208 \pm 40 \%)$. The magnitude of the increase in lactate output correlated with the degree of tension suppression produced by the intervention rather than the nature of the intervention. When the concentration of DNP was increased to $2.5 \pm 10^{-3} \mathrm{M}$, the degree of tension suppression was greater than hypoxia (13 \pm 13 vs. $27 \pm 5 \%$ of control after $10 \mathrm{~min}$ ), and the increase in venous lactate efflux rate was also greater $(550 \pm 118$ vs. $506 \pm 83 \%$ after $10 \mathrm{~min})$. The higher concentration of DNP also depressed high energy phosphate content comparable to hypoxia (Table I).

The observations described above suggest that during modest inhibition of oxidative metabolism in this preparation, the acceleration of glycolysis was capable of producing enough high energy phosphates to maintain total cellular content at normal levels. Despite this, tension was markedly suppressed, which suggested that either the glycolytically derived high energy phosphates were not as readily available for supporting

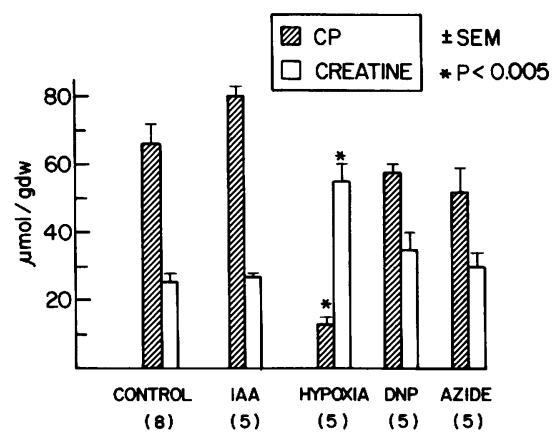

Figure 5. Myocardial content of phosphocreatine (CP) and creatine after 10-min exposure to interventions designed to inhibit selectively glycolysis (IAA) or oxidative metabolism (hypoxia, DNP, azide). For more detailed description of specific interventions see legend to Fig. 3 . Values represent mean \pm SEM with number of preparations indicated in parentheses. Asterisks indicate statistical significance $(P<$ $0.005)$ compared with the control value. Temperature was $37^{\circ} \mathrm{C}$, and heart rate $75 \mathrm{bpm}$.

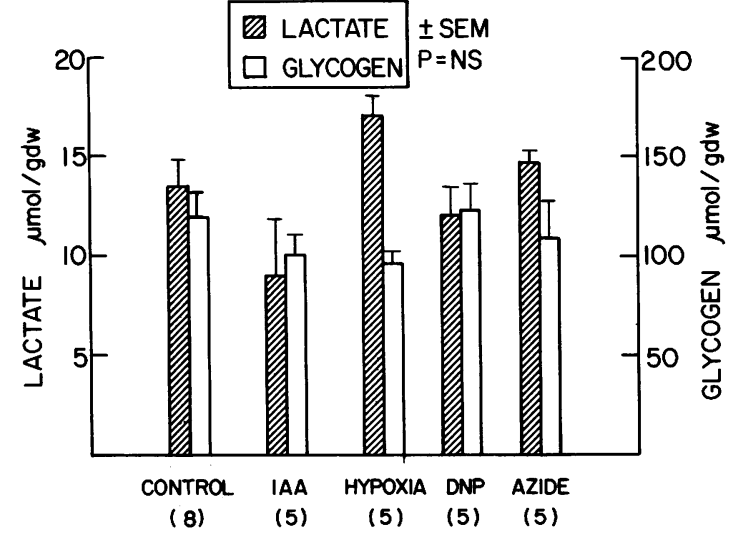

Figure 6. Myocardial content of lactate and glycogen after 10-min exposure to interventions designed to inhibit selectively glycolysis (IAA) or oxidative metabolism (hypoxia, DNP, azide). For more detailed description of specific interventions see legend to Fig. 3. Values represent mean \pm SEM with number of preparations indicated in parentheses. Differences in lactate and glycogen content were not statistically different from control. Temperature was $37^{\circ} \mathrm{C}$, and heart rate $75 \mathrm{bpm}$.

tension development (i.e., they are compartmentalized), or that other factors were responsible for the loss of tension. To evaluate the latter possibility, the contribution of acidosis to the suppression of tension during inhibition of oxidative metabolism was investigated. Fig. 8 compares changes in $\mathrm{pH}_{0}$ and tension measured during successive 10-min exposure periods to hypoxia with and without glucose present in six preparations. In the absence of glucose, hypoxia caused a significantly greater suppression of tension than when glucose was present $(7 \pm 3$ vs. $22 \pm 8 \%$ of control after $10 \mathrm{~min}$, respectively, $P<0.02)$, yet fall in $\mathrm{pH}_{0}$ was significantly less $(-0.07 \pm 0.03$ vs. $-0.17 \pm 0.04 \mathrm{U}$ after $10 \mathrm{~min}, P<0.01)$.

Since the $\mathrm{pH}$ of the hypoxic perfusate with or without glucose was identical, the magnitude of the change in $\mathrm{pH}_{0}$ must be a reflection of the magnitude of the intracellular $\mathrm{pH}$ change. These findings make it unlikely that the development of intracellular acidosis is a major factor contributing to the suppression of tension during hypoxia. In two experiments, similar results were obtained when the effects of $10^{-5} \mathrm{M}$ DNP in the presence and absence of glucose were compared. We also investigated the possibility that the lesser degree of $\mathrm{K}^{+}$ loss during suppression of oxidative compared to glycolytic metabolism might be related to the opposite direction of $\mathrm{pH}_{0}$ change, particularly since respiratory acidosis has been shown to induce a net $\mathrm{K}^{+}$uptake in this preparation (12). Fig. 9 shows a preparation in which an attempt was made to prevent the fall in $\mathrm{pH}$ during exposure to $10^{-3} \mathrm{M} \mathrm{Na}$ azide by increasing the $\mathrm{pH}$ of the perfusate containing $\mathrm{Na}$ azide from 7.30 to 7.55 (by lowering the $\mathrm{CO}_{2}$ content from 5 to $2 \%$ ). In three preparations, the fall in $\mathrm{pH}_{0}$ during exposure to $\mathrm{Na}$ azide, $\mathrm{pH} 7.55$, was completely reversed $\left(\Delta \mathrm{pH}_{0}=+0.10 \pm 0.05\right.$ $\mathrm{U}$ after $10 \mathrm{~min})$. The level of $\left[\mathrm{K}^{+}\right]_{0}$ accumulation, however, was reduced when compared to exposure to $\mathrm{Na}$ azide with normal $\mathrm{pH}$ in the same preparations $(0.13 \pm 0.07$ vs. $0.37 \pm 0.10$ $\mathrm{mM}$ after $10 \mathrm{~min}$, respectively). Even though the high $\mathrm{pH}$ perfusate may have only partially reversed the intracellular acidosis produced by $\mathrm{Na}$ azide, the effect was to decrease rather than increase cellular $\mathrm{K}^{+}$loss. 







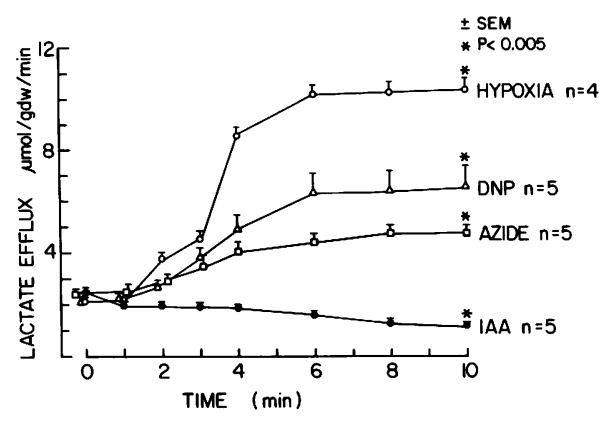

Figure 7. Lactate efflux rate during 10-min exposures to various interventions designed to inhibit selectively either glycolysis (IAA) or oxidative metabolism (hypoxia, DNP, azide). For more detailed description of specific interventions see legend to Fig. 3. Values are mean \pm SEM. Asterisks indicate statistical significance $(P<0.005)$ of the change in lactate efflux rate after 10 min compared with the control value. Temperature $37^{\circ} \mathrm{C}$, and heart rate $75 \mathrm{bpm}$.

Because IAA is not a completely specific metabolic inhibitor, the effects of several other interventions designed to inhibit glycolysis selectively were also studied. These included (a) removal of glucose from the perfusate; $(b)$ removal of glucose and addition of $5 \mathrm{mM} \mathrm{Na}$ acetate (19); (c) removal of glucose and addition of $20 \mathrm{mM}$ 2-deoxyglucose, or $(d)$ removal of glucose and addition of a lower dose of IAA, $10^{-4} \mathrm{M}$. In all cases, $3 \mathrm{mM}$ pyruvate was present as substrate for oxidative metabolism. A 10-min exposure to these interventions caused modest $\left[\mathrm{K}^{+}\right]_{0}$ accumulation $(0.2-0.8 \mathrm{mM}$, not significantly different between the four interventions) and a mild suppression of developed tension (77-93\% of control) (Table II). These changes were qualitatively similar to the effects of $10^{-3} \mathrm{M}$ IAA without glucose. Total cellular high energy phosphates levels



Figure 8. Effect of glucose on $\mathrm{pH}_{0}$ and tension during hypoxia. $A$ shows original records of changes in $\mathrm{pH}_{0}$ and tension $(\mathrm{T})$ during exposure of a preparation to $10 \mathrm{~min}$ of hypoxia with glucose present as substrate $(\mathbf{H}+\mathbf{G L U})$, and, after recovery, to hypoxia without glucose (H - GLU). $B$ and $C$ compare the mean changes in normalized tension $\left(\mathrm{T} / \mathrm{T}_{0}\right)$ and $\mathrm{pH}_{0}$ in six preparations during the two interventions. Error bars indicate SEM. Statistical significance was evaluated with a repeated measures analysis of variance. Temperature was $37^{\circ} \mathrm{C}$, and heart rate $75 \mathrm{bpm}$.

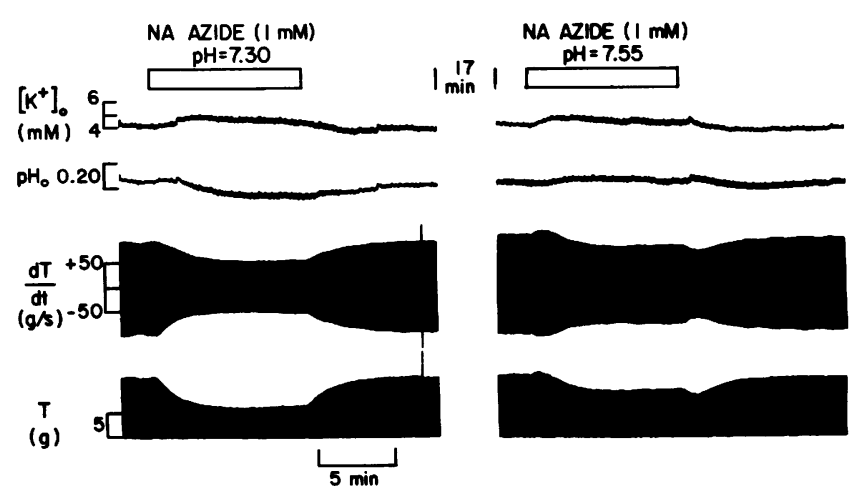

Figure 9. The effect of $\mathrm{pH}$ on $\left[\mathrm{K}^{+}\right]_{0}$ accumulation during exposure to $\mathrm{Na}$ azide. A preparation perfused with standard perfusate, $\mathrm{pH} 7.30$, was exposed to perfusate containing $10^{-3} \mathrm{M} \mathrm{Na}$ azide, $\mathrm{pH} 7.30$, for 10 min, and changes in $\left[\mathrm{K}^{+}\right]_{0}, \mathrm{pH}_{0}$, in tension $(\mathrm{T})$ and its first derivative (dT/dt) were recorded. After recovery in standard perfusate, the preparation was exposed again to $\mathrm{Na}$ Azide with the $\mathrm{pH}$ adjusted to 7.55 by equilibration with $2 \% \mathrm{CO}_{2}$ instead of $5 \% \mathrm{CO}_{2}$. The fall in $\mathrm{pH}_{0}$ which occurred during the first exposure to $\mathrm{Na}$ azide was reversed, yet $\left[\mathrm{K}^{+}\right]_{0}$ accumulation was slightly decreased. The positive inotropic effect of alkalosis was also apparent. Temperature was $37^{\circ} \mathrm{C}$, and heart rate $75 \mathrm{bpm}$.

were not significantly depressed by any of these interventions (Table II). The smaller amount of $\left[\mathrm{K}^{+}\right]_{0}$ accumulation observed with these interventions compared to $10^{-3} \mathrm{M}$ IAA was probably related to their less effective suppression of glycolysis, since the decrease in lactate efflux (ranging from 4 to $23 \%$ ) was not as great as that produced by $10^{-3} \mathrm{M}$ IAA (40\%) (Table II, Fig. 10).

Further evidence that these interventions did not completely suppress glycolysis was obtained from experiments in which lactate efflux was monitored during exposure to each regimen for a 20-min period, the last $10 \mathrm{~min}$ of which the perfusate was also made hypoxic. As seen in Fig. 10, none of the interventions, except for $10^{-3} \mathrm{M}$ IAA, completely prevented the hypoxia-induced increase in lactate efflux. Glucose-free perfusate with acetate present did not suppress the increase in lactate output during hypoxia at all (see Fig. 7 for comparison), whereas glucose-free perfusate alone or with $20 \mathrm{mM}$ 2-deoxyglucose or $10^{-4} \mathrm{M}$ IAA present only partially suppressed (by 41-59\%) the increase in lactate output during hypoxia (Table III). The consequences of even partially blunting the ability of glycolysis to accelerate during hypoxia were profound. Compared to hypoxia with glucose present, during hypoxia without glucose tension suppression was more complete, contracture tension developed earlier, $\left[\mathrm{K}^{+}\right]_{0}$ accumulation was greater, and cellular high energy phosphates were more rapidly depleted (Fig. 8 and Table III). If, in addition to removing glucose, 2deoxyglucose or IAA were added to the perfusate, the deterioration in cardiac function during hypoxia was even more severe, as manifested by complete loss of twitch tension, severe irreversible contracture, large $\left[\mathrm{K}^{+}\right]_{0}$ accumulation, marked action potential shortening leading to inexcitability, and severe depletion of high energy phosphates (Table III).

\section{Discussion}

Evidence that high energy phosphates generated by glycolysis were used preferentially to support membrane function has 


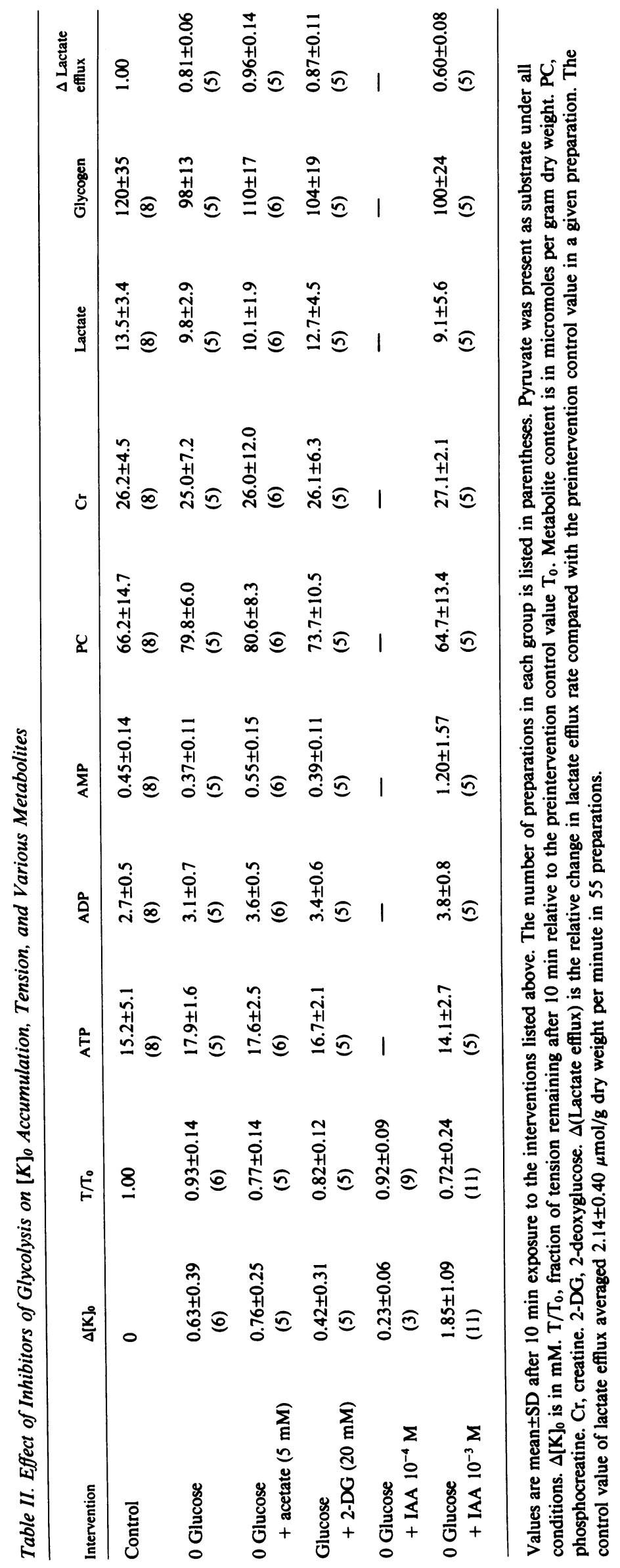




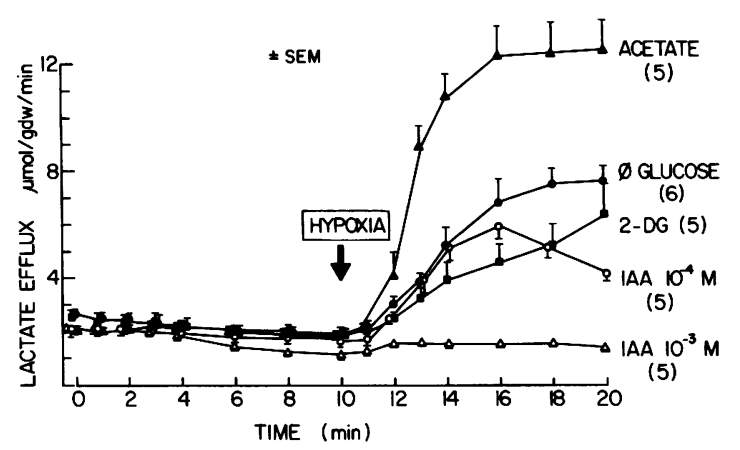

Figure 10. Effect of various interventions inhibiting glycolysis on lactate efflux rate. At time zero, preparations were exposed to perfusate containing pyruvate as substrate in which glucose was omitted $(\bullet)$, and either $5 \mathrm{mM} \mathrm{Na}$ acetate ( $\triangle$ ), $20 \mathrm{mM}$ 2-deoxyglucose ( () , or $10^{-4} \mathrm{M}(0)$ or $10^{-3} \mathrm{M}(\Delta)$ IAA was added. After $10 \mathrm{~min}$ of exposure to these regimens, the perfusate was made hypoxic for an additional $10 \mathrm{~min}$. Error bars indicate SEM, and number of preparations are in parentheses. Temperature was $37^{\circ} \mathrm{C}$, and heart rate $75 \mathrm{bpm}$.

been presented previously in erythrocytes (1), and more recently in vascular smooth muscle (3). In the latter case it was also demonstrated that oxidatively generated high energy phosphates were used preferentially for tension development. This finding is consistent with the proposal in skeletal and cardiac muscle that a phosphocreatine energy shuttle which transports high energy phosphates from the mitochondria to the cytoplasm may be the preferential supplier of metabolic energy for muscle contraction $(2,20,21)$. In cardiac muscle, other indirect evidence suggesting compartmentation of metabolic energy has been presented. Gudbjarnasson et al. (22) postulated that the more rapid fall in phosphocreatine than in ATP during ischemia might be related to a breakdown of the phosphocreatine energy shuttle, thus effectively trapping ATP within the mitochondria. MacLeod and Daniel (4) found that in guinea pig papillary muscles, exposure to hypoxia caused marked shortening of the action potential and loss of tension. The action potential shortening could be largely prevented by elevating the perfusate glucose content from 5 to $50 \mathrm{mM}$ although contractile performance was not improved. More recently, several investigators using models of low-flow ischemia in Langendorff rat hearts have shown that concomitant inhibition of glycolytic or oxidative metabolism during low flow ischemia produced no significant differences in cellular content of high energy phosphates, but inhibition of glycolysis markedly accelerated the onset of irreversible myocardial damage, as assessed by development of ischemic contracture or enzyme release upon reperfusion (5-7).

Similarly, in cultured neonatal rat heart cells it has been shown that the susceptibility of the sarcolemmal membrane to damage by phospholipases (which have been incriminated in the pathogenesis of ischemic damage to the sarcolemma) was enhanced when glycolysis was inhibited, but not when oxidative metabolism was suppressed, despite similar levels of total cellular high energy phosphates (8). Recently, Hasin and Barry (10) reported that in cultured chick embryo myocytes, membrane depolarization and ${ }^{42} \mathrm{~K}$-uptake were more sensitive to selective inhibition of glycolytic than oxidative metabolism, despite a smaller depression of high energy phosphates in the former case. Conversely, contractile amplitude was much more sensitive to inhibition of oxidative metabolism. From these studies it has been postulated that high energy phosphates derived from glycolysis are preferentially used by the cardiac sarcolemma and help to prevent irreversible damage during insults such as ischemia. The results of the present study both confirm and extend these findings. Using cellular $\mathrm{K}^{+}$loss as a marker of sarcolemmal function, we showed that suppression of glycolysis using $10^{-3} \mathrm{M}$ IAA (in glucose-free perfusate containing pyruvate as substrate for oxidative metabolism) resulted in marked $\mathrm{K}^{+}$loss, while causing only a modest suppression of twitch tension (Figs. 2 and 3). Total cellular content of high energy phosphates was normal, presumably because oxidation of exogenous pyruvate and endogenous fatty acids allowed oxidative metabolism to compensate for the reduced contribution of glycolysis to the total high energy phosphate pool. In contrast, inhibition of oxidative metabolism with hypoxia, DNP, or Na azide caused only a modest $\mathrm{K}^{+}$ loss but markedly suppressed tension. Despite the marked degree of contractile dysfunction with $10^{-5} \mathrm{M} \mathrm{DNP}$ and $10^{-3}$ $\mathrm{M} \mathrm{Na}$ azide (Figs. 1 and 3), total cellular levels of high energy phosphates remained normal, presumably due to enhanced glycolysis (Table I and Fig. 7). During more complete suppression of oxidative metabolism with hypoxia or higher doses of DNP $\left(2.5 \times 10^{-5} \mathrm{M}\right)$, total cellular content of higher energy phosphates did decrease as a result of the inability of glycolysis to compensate fully, and although twitch tension was further suppressed, $\mathrm{K}^{+}$loss still did not increase greatly (Table I).

Our interpretation of these findings is that during inhibition of glycolysis, despite normal total cellular levels of high energy phosphates, high energy phosphates generated oxidatively were not effectively used by the sarcolemma to prevent $\mathrm{K}^{+}$loss; conversely, during suppression of oxidative metabolism, high energy phosphates generated via glycolysis were not effectively used to maintain twitch tension despite (in the case of DNP and $\mathrm{Na}$ azide) normal total cellular levels of high energy phosphates. This functional compartmentation of glycolytic vs. oxidative metabolism is only partial, since simultaneous inhibition of both metabolic pathways had much more severe consequences on sarcolemmal and contractile function than that produced by inhibition of either pathway alone (Table III), as has been observed in other preparations (23). For example, if glycolytically generated high energy phosphates could not be used at all by the contractile apparatus (complete compartmentation), then one would expect hypoxia alone to have had the same effect on mechanical performance as hypoxia and inhibition of glycolysis, i.e., complete loss of developed tension and severe contracture, which was not observed. Finally, it should be noted that under our experimental conditions, glucose and pyruvate were the only exogenous substrates supplied to the heart. It is possible that if other substrates, e.g., free fatty acids, were present, the evidence suggesting compartmentation could not be elicited.

The validity of interpreting our findings as evidence of compartmentation rests on two assumptions: first, that the methods used to suppress glycolytic and oxidative metabolism were selective and did not have major nonspecific effects on cellular $\mathrm{K}^{+}$balance or tension development, and second, that the changes in cellular $\mathrm{K}^{+}$loss and tension development were directly related to metabolic factors and not to secondary factors such as intracellular pH changes. Regarding the specifically of the metabolic inhibitors, the essentially similar results obtained with hypoxia, DNP, and $\mathrm{Na}$ azide on $\mathrm{K}^{+}$loss and tension development, despite different mechanisms of mito- 





chrondial inhibition, suggest that their effects were related specifically to the suppression of oxidative metabolism and not to nonspecific actions of these agents on cardiac performance. IAA is a general sulfhydryl group inhibitor in high concentrations which may suppress many enzyme systems (24). At the $10^{-3} \mathrm{M}$ dosage and 10-min exposure period used in this study, however, total cellular levels of high energy phosphates remained normal, and the only detectable metabolic effect was a decrease in lactate output consistent with a suppression of glycolysis. $10^{-3} \mathrm{M}$ IAA also had no direct effect on $\mathrm{Na}^{+}-\mathrm{K}^{+}$ATPase activity in sarcolemmal vesicles isolated from dog or rabbit ventricle (Philipson, K. D., personal communication). An effect of IAA on cellular $\mathrm{K}^{+}$loss has been observed in a number of tissues, although the precise correlation with the inhibition of glycolysis is unestablished (24).

In our preparation, the strongest evidence that the effect of IAA on $\mathrm{K}^{+}$loss was related to inhibition of glycolysis and not a nonspecific effect is that other interventions which inhibited glycolysis to a lesser extent, such as glucose-free perfusate containing pyruvate and/or acetate or 2-deoxyglucose, consistently resulted in significant $\left[\mathrm{K}^{+}\right]_{0}$ accumulation with little effect on tension or cellular high energy phosphate content (Tables II and III). Furthermore, if the dosage of IAA was reduced to $10^{-4} \mathrm{M}$ so that the suppression of both basal lactate efflux rate (Table II) and the increase in lactate efflux rate in response to hypoxia (Table III) was comparable to the interventions listed above, the magnitude of $\left[\mathrm{K}^{+}\right]_{0}$ accumulation was similar to the other interventions (Table III). Thus, in comparison to the other interventions suppressing glycolysis, IAA did not appear to have any nonspecific effect on $\mathrm{K}^{+}$loss out of proportion to its effect on glycolysis. However, we cannot absolutely exclude a nonspecific effect of IAA on $\mathrm{K}^{+}$ permeability which would invalidate our interpretation of the findings.

The second criticism of interpreting our results in terms of compartmentation of metabolic energy relates to whether the changes in cellular $\mathrm{K}^{+}$balance and tension were caused directly by metabolic factors or were related to secondary factors, such as intracellular pH changes. The role of acidosis was evaluated in the experiments described in Figs. 8 and 9, and it was concluded that the opposite effects of inhibition of glycolytic vs. oxidative metabolism on $\mathrm{pH}$ were unlikely to account for the results. It can be argued that extracellular pH measurements may not have accurately reflected changes in intracellular pH during these interventions. Direct intracellular pH measurements using ${ }^{31} \mathrm{P}$ NMR, however, show good agreement with our extracellular pH measurements under similar conditions. Matthews et al. (25), for example, found that after 10 min of hypoxia with glucose present as substrate, $\mathrm{pH}_{\mathrm{i}}$ decreased by $0.14 \mathrm{U}$ in the Langendorff rat heart compared with the extracellular $\mathrm{pH}$ fall of $0.17 \mathrm{U}$ we measured in the septum. There is considerable evidence supporting a direct link between cellular $\mathrm{K}^{+}$balance and metabolic state. The activity of the $\mathrm{Na}^{+}-\mathrm{K}^{+}$pump obviously depends directly on the availability of ATP. However, during metabolic insults such as ischemia and hypoxia, several investigators have suggested that increased $\mathrm{K}^{+}$efflux rather than decreased $\mathrm{K}^{+}$ influx is the more important factor causing cellular $\mathrm{K}^{+}$loss $(10,26-28)$.

Consistent with this hypothesis, two groups of investigators using the patch clamp technique in isolated ventricular cells have recently shown that a sarcolemma $\mathrm{K}^{+}$channel becomes highly permeable when ATP content is reduced to low levels or removed from the perfusate $(29,30)$. These observations suggest that cellular $\mathrm{K}^{+}$loss during inhibition of metabolism is not a mere bystander phenomenon, but has a direct metabolic basis. It is likely that contractile dysfunction during hypoxia and other interventions also has a direct metabolic basis, especially since acidosis (the leading alternative) was excluded as a major factor (Fig. 8). However, the precise etiology of contractile dysfunction during metabolic inhibition is not fully understood at the present time. Action potential configuration is determined by membrane ionic conductance changes, which are not thought to be direct energy consuming processes, with the possible exception of the slow $\mathrm{Ca}^{++}$channel (31). Therefore, it is not surprising that changes in action potential duration did not parallel changes in $\mathrm{K}^{+}$loss during metabolic inhibition (Fig. 3).

If high energy phosphates derived from glycolytic vs. oxidative metabolism are used preferentially for different functions in cardiac muscle, the mechanism of this functional compartmentation remains to be elucidated. It is unlikely that a difference in the $K_{\mathrm{m}}$ for ATP use by sarcolemmal vs. contractile processes could explain the findings, since severe impairment of either sarcolemmal function (i.e., marked $\mathrm{K}^{+}$ loss) or contractile function could be produced by selective metabolic inhibition without depressing total cellular high energy phosphate content (Figs. 3-5). Thus, if all intracellular high energy phosphates were equally available for use by sarcolemma or the contractile apparatus, no functional abnormalities should have developed, even if the $K_{\mathrm{m}}$ values were different. Another possibility is that two populations of cells exist in this preparation, one more dependent on glycolysis than the other. However, there is no direct evidence to support this possibility and the fact that evidence for compartmentation of metabolic energy has been found in diverse cardiac preparations ranging from intact working hearts to cultured myocytes obtained from a variety of species (4-10) makes this explanation unlikely. It is more plausible that the functional compartmentation of glycolytic vs. oxidative metabolism has an intracellular basis.

It may be speculated that the close proximity of the mitochondria to the myofibrils enhances the delivery of oxidatively generated high energy phosphates to the contractile apparatus relative to high energy phosphates generated by other metabolic pathways. Although still controversial, it has been proposed that the phosphocreatine energy shuttle, whereby ATP generated intramyocardially is released into the cytosol in the form of phosphocreatine, may be the preferential source of ATP delivery to the contractile apparatus via the interaction of phosphocreatine with myosin-bound creatine kinase $(2,20$, $21)$. If this model is correct, the ability of glycolytically generated ATP to supply the contractile apparatus might be more limited, due to its lesser proximity and the possibility that cytosolic ATP is not as readily convertible to phosphocreatine as mitochondrially generated ATP, as has been reported in skeletal muscle (2). Conversely, strategically positioned glycolytic enzymes could result in more efficient delivery of high energy phosphates to sites of utilization in the sarcolemma, accounting for the lesser ability of oxidatively generated high energy phosphates to preserve normal sarcolemmal integrity as manifested by $\mathrm{K}^{+}$loss. In erythrocytes, evidence has been presented suggesting that membrane-bound glycolytic enzymes 
may be a preferential source of ATP delivery to the $\mathrm{Na}^{+}-\mathrm{K}^{+}$ pump (1). Glycogenolytic enzyme complexes also have been demonstrated to be bound to the sarcoplasmic reticulum in cardiac muscle (32). These mechanisms could potentially account for the functional compartmentation of glycolytic vs. oxidative mechanism we have observed in the rabbit ventricle.

The degree of compartmentation in this preparation is not complete, since inhibition of glycolysis led to some loss of tension and inhibition of oxidative metabolism caused some $\mathrm{K}^{+}$loss. It might appear paradoxical that there should be any $\mathrm{K}^{+}$loss during suppression of oxidative metabolism, since glycolytic flux is so greatly increased (Fig. 7). It is possible that the $\mathrm{K}^{+}$loss under these conditions is due not to a membrane conductance change, but is coupled to the movement of intracellular generated anions (e.g., lactate) from the intracellular to extracellular compartment, so that neutral charge balance is maintained across the sarcolemma. However, voltage clamp studies have identified an increase in background $\mathrm{K}^{+}$conductance during hypoxia in cat papillary muscles (33), which suggests that a change in sarcolemma $\mathrm{K}^{+}$conductance contributes directly to $\mathrm{K}^{+}$loss. A second possibility is that during inhibition of oxidative metabolism the increase in glycolytic flux also involves activation of glycolytic enzymes not associated specifically with the sarcolemma (e.g., cytosolic or sarcoplasmic reticulum bound), so that competition for substrate limits ATP synthesis by the fraction of glycolytic enzyme specifically associated with the sarcolemma. This hypothesis implies a further compartmentation of glycolytic metabolism in the sense that not all glycolytically generated ATP would have the same preferential access to sites of use by the sarcolemma to prevent $\mathrm{K}^{+}$loss. The observation that $10^{-3} \mathrm{M}$ IAA consistently produced an irreversible contracture, beginning after an average of $4.0 \pm 2.2 \mathrm{~min}$, may support this hypothesis. After prolonged exposure to hypoxia, contracture also develops, and occurs much sooner in the absence of exogenous glucose (34). Like the hypoxia-induced contracture (35), lowering $\left[\mathrm{Ca}^{++}\right]_{0}$ did not relax the IAA-induced contracture, which potentially indicates a similar mechanism. A feature common to these interventions producing contracture may be the suppression of glycogenolysis, directly in the case of $10^{-3} \mathrm{M}$ IAA and by depletion of glycogen stores in the case of hypoxia without exogenous substrate. In view of the close association of glycogenolytic enzyme complexes with the sarcoplasmic reticulum in heart (32), it is conceivable that glycogenolysis preferentially supplies ATP to the relaxing system. A functional compartmentation of ATP generated from exogenous glucose vs. endogenous glycogen has been already demonstrated in vascular smooth muscle (36), and Dennis et al. (37) have previously postulated a similar phenomenon in cardiac muscle in order to explain the difference in reperfusion arrhythmias between glucose and pyruvate perfused hearts. We are currently investigating this possibility in the septal preparation.

\section{Acknowledgments}

We thank Drs. K. I. Shine, G. A. Langer, and K. D. Philipson for their critical comments.

This work was supported by Grants-In-Aid from the American Heart Association, Greater Los Angeles Affiliate, and from the American Heart Association, grant 1 R23 HL27846 from the U. S. Public Health Service, and by the Arthur Dodd Fuller Fund and Laubisch Endowment.

\section{References}

1. Parker, J. C., and J. F. Hoffman. 1967. The role of membrane phosphoglycerate kinase in the control of glycolytic rate by active cation transport in human red blood cells. J. Gen. Physiol. 50:893916.

2. Bessman, S. P., and P. J. Geiger. 1981. Transport of energy in muscle: the phosphorylcreatine shuttle. Science (Wash. DC). 211:448452.

3. Paul, R. J. 1983. Functional compartmentalization of oxidative and glycolytic metabolism in vascular smooth muscle. Am. J. Physiol. 244:C399-C409.

4. MacLeod, D. P., and E. E. Daniel. 1965. Influence of glucose on the transmembrane action potential of anoxic papillary muscle. $J$. Gen. Physiol. 48:887-899.

5. Bricknell, O. L., and L. H. Opie. 1978. Effects of substrates on tissue metabolic changes in the isolated rat heart during underperfusion and on release of lactate dehydrogenase and arrhythmias during reperfusion. Circ. Res. 43:102-115.

6. Bricknell, O. L., P. S. Daries, and L. H. Opie. 1981. A relationship between adenosine triphosphate, glycolysis and ischemic contracture in the isolated rat heart. J. Mol. Cell. Cardiol. 13:941945.

7. Higgins, T. J. C., and P. J. Bailey. 1983. The effects of cyanide and iodoacetate intoxication and ischaemia on enzyme release from the perfused rat heart. Biochim. Biophys. Acta. 762:67-75.

8. Higgins, T. J. C., P. J. Bailey, and D. Allsopp. 1982. The interrelationship between cellular metabolic status and susceptibility of heart cells to attack by phospholipase. J. Mol. Cell. Cardiol. 14:645654.

9. Doorey, A. J., and W. H. Barry. 1983. The effects of inhibition of oxidative phosphorylation and glycolysis on contractility and high energy phosphate content in cultured chick heart cells. Circ. Res. 53:192-201.

10. Hasin, Y., and W. H. Barry. 1984. Myocardial metabolic inhibition and membrane potential, contraction, and potassium uptake. Am. J. Physiol. 247:H322-H329.

11. Weiss, J., and K. I. Shine. 1982. $\left[\mathrm{K}^{+}\right]_{0}$ accumulation and electrophysiological alterations during early myocardial ischemia. Am. J. Physiol. 243:H318-H327.

12. Poole-Wilson, P. A., and G. A. Langer. 1975. Effect of pH on ionic exchange and function in rat and rabbit myocardium. Am. J. Physiol. 229:570-581.

13. Rau, E. E., and G. A. Langer. 1978. Dissociation of energetic state and potassium loss from anoxic myocardium. Am. J. Physiol. 235:H537-H543.

14. Shelburne, J. C., S. D. Serena, and G. A. Langer. 1967. Ratetension staircase in rabbit ventricular muscle: relation to ionic exchange. Am. J. Physiol. 213:1115-1124.

15. Woodbury, J. W., and A. J. Brady. 1956. Intracellular recording from moving tissue with a flexibly mounted ultramicroelectrode. Science (Wash. DC). 123:100-101.

16. Hill, J. L., L. S. Gettes, M. R. Lynch, and N. C. Hebert. 1978. Flexible valinomycin electrodes for on-line determination of intravascular and myocardial K+. Am. J. Physiol. 235:H455-H459.

17. Guttman, I., and A. W. Wahlefeld. 1974. Lactate determination with lactate dehydrogenase and NAD. In Methods of Enzymatic Analysis. H. Bergmeyer, editor. Academic Press, Inc., New York. 1464-1468.

17a. Dubiak, G. R., and A. Scarpa. 1983. ${ }^{31} \mathrm{P}$ NMR studies of single muscle cells isolated from Barnacle depressor muscle. Biochemistry. 22:3531-3536.

18. Keppler, D., and K. Decker. 1974. Glycogen determination with amyloglucosidase. In Principles of Enzymatic Analysis. H. Bergemeyer, editor. Academic Press, Inc., New York. 1127-1131.

19. Williamson, J. R. 1965. Glycolytic control mechanisms: I. Inhibition of glycolysis by acetate and pyruvate in isolated perfused rat heart. J. Biol. Chem. 240:2308-2321. 
20. Bittl, J. A., and J. S. Ingwall. 1983. Direct investigation of creatine kinase kinetics and ATP synthesis in the isolated rat heart: A ${ }^{31}$ P NMR study. Circulation. 68(Suppl. III)III-E. (Abstr.)

21. Micell, M. V., J. A. Hoerter, and W. E. Jacobus. 1983. Evidence supporting the phosphocreatine-ATP energy transport shuttle in perfused rabbit hearts: A ${ }^{31} \mathrm{P}$ NMR saturation transfer study. Circulation. 68(Suppl. III):III-65. (Abstr.)

22. Gudbjarnasson, S., P. Mathes, and K. G. Ravens. 1970. Functional compartmentation of ATP and creatine phosphate in heart muscle. J. Mol. Cell. Cardiol. 1:325-339.

23. Apstein, C. S., L. Deckelbaum, L. Hagopian, and W. B. Hood. 1978. Acute cardiac ischemia and reperfusion: contractility, relaxation, and glycolysis. Am. J. Physiol. 235:H637-H648.

24. Webb, J. L. Enzyme and Metabolic Inhibitors, Vol. 3. 1966. Academic Press, Inc., New York. 1-228.

25. Matthews, P. M., G. K. Radda, and D. J. Taylor. 1981. A ${ }^{31}$ P NMR study of metabolism in the hypoxic perfused rat heart. Biochem. Soc. Trans. 9:236-237.

26. Kleber, A. G. 1983. Resting membrane potential, extracellular potassium activity and intracellular sodium activity during acute global ischemia in isolated perfused guinea pig hearts. Circ. Res. 52:442-450.

27. Rau, E. E., K. I. Shine, and G. A. Langer. 1977. Potassium exchange and mechanical performance in anoxic mammalian myocardium. Am. J. Physiol. 232:H85-H94.

28. Weiss, J., and K. I. Shine. 1982. Extracellular $\mathrm{K}^{+}$accumulation during myocardial ischemia in isolated rabbit heart. Am. J. Physiol. 242:H619-H628.
29. Noma, A. 1983. ATP regulated $\mathrm{K}^{+}$channels in cardiac muscle. Nature (Lond.). 305:147-148.

30. Trube, G., and J. Heschler. 1983. Potassium channels in isolated patches of cardiac cell membrane. Naunyn-Schmiedebergs Arch. Pharmakol. 322:255.

31. Sperelakis, N., and J. A. Schneider. 1976. A metabolic control mechanism for calcium ion influx that may protect the ventricular myocardial cell. Am. J. Cardiol. 37:1079-1085.

32. Entman, M. L., K. Kaniike, M. A. Goldstein, T. E. Nelson, E. P. Barnet, T. W. Futch, and A. Schwartz. 1976. Association of glycogenolysis with cardiac sarcoplasmic reticulum. J. Biol. Chem. 251:3140-3146.

33. Vleugels, A., J. Vereecke, and E. Carmeliet. 1980. Ionic currents during hypoxia in voltage-clamped cat ventricular muscle. Circ. Res. 47:501-508.

34. Henry, P. D., B. E. Sobel, and E. Braunwald. 1974. Protection of hypoxic guinea pig hearts with glucose and insulin. Am. J. Physiol. 226:309-313.

35. Nayler, W. G., P. A. Poole-Wilson, and A. Williams. 1979. Hypoxia and calcium. J. Mol. Cell. Cardiol. 11:683-706.

36. Lynch, R. M., and R. J. Paul. 1983. Compartmentation of glycolytic and glycogenolytic metabolism in vascular smooth muscle. Science (Wash, DC.). 222:1344-1346.

37. Dennis, S. C., D. J. Hearse, and D. J. Coltart. 1982. Metabolic effects of substrates on the isolated guinea-pig heart in relationship to arrhythmias during reperfusion. Cardiovasc. Res. 16:209-219. 